\title{
QUANTIFICATION OF HYDROGEOLOGICAL PARAMETERS BY GEOPHYSICAL METHODS
}

\author{
Snezana Komatina \\ Geophysical Institute, Karadjordjeva 48, 11000 Beograd, Yugoslavia
}

Within hydrogeological exploration, geophysical methods have a significant role in solving following problems:

- possibilities of safe analyses of aquifer geometry and structural properties;

- monitoring of aquifer contamination by mineral and organic deposits;

- defining relevant indications on a hanging-wall permeability characteristics and aquifer hydrodinamic parameters;

- indicating groundwater level;

- analysis of groundwater chemistry;

- determining clay facii in a complex of hanging-wall sediments;

- exploration of velocity transfer for wet front and pollutant within.

According to regional geophysical exploration, the basis for: regional measures for water resources utilization and protection planning and production, space plan production, identifying safe zones for hazardous waste placement, distinguishing zones where groundwaters are not protected and for which the prophylactic protective measures have to be planned, etc. Detailed geophysical investigations on overburden sediments are significant in connection with drawing up plans for industrial, agricultural and other objectives.

As a case history, an area of Djerdap reservoir on the Danube river (Serbia, Yugoslavia) is presented. Namely, complex geophysical exploration has been done in order to prevent and moderate a harmful influence of the performed reservoir on the environment (increased groundwater infiltration from the reservoir into surrounding rocks, permanent groundwater level raising, etc.). In that sense, a hydrogeophysical investigation was useful in delineation of the aquifer, obtainment of appropriate parameters (groundwater level, groundwater chemistry, clay content, filtration characteristics and physical parameters of geological formations), as well as mapping of the aquifer vulnerability.

In the exploratory test site, several geophysical methods were applied (seismics, well-logging, electric and electromagnetic method). According to obtained results, vulnerability to pollution was evaluated through following factors: (1) thickness of low-permeable hanging-wall $\mathrm{d}(\mathrm{m})$; (2) groundwater level (in other words, thickness of aeration zone $h(m)$ ); (3) grain-size distribution of hanging-wall; (4) filtration coefficients of rocks within hanging-wall $K(\mathrm{~m} / \mathrm{s})$. 

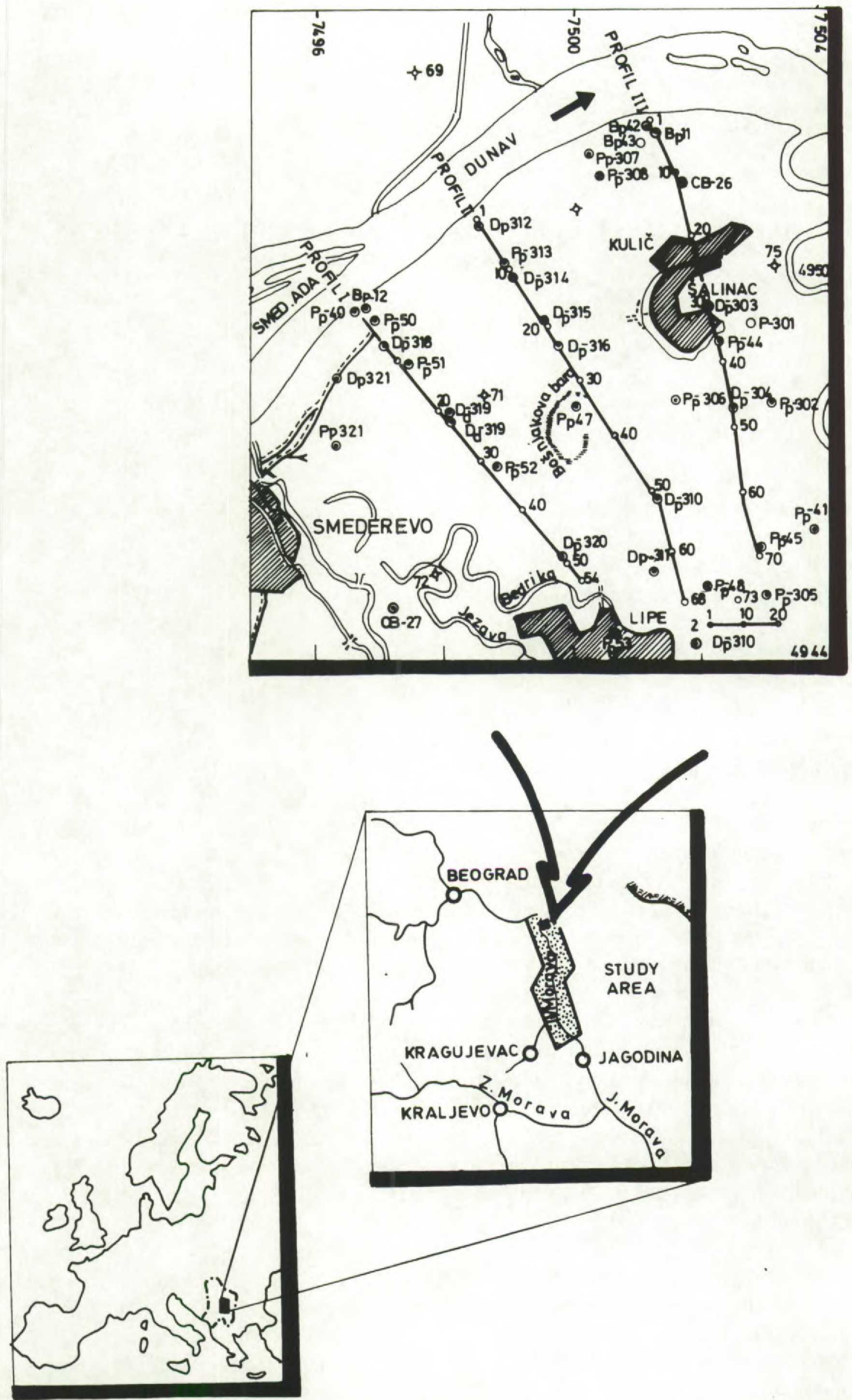

Fig.1. Study area - Salinac field near Smederevo. Profiles of geoelectric measurements (Komatina S., 1996). 
According to geophysical interpretation, it was concluded that:

- depth of alluvial plain is 12-25 m (gravely layer: 5-18 m, hanging-wall: 3-11 m);

- filtration coefficient: $\mathrm{K}=1,0 \cdot 10^{-4}$ to $1.0 \cdot 10^{-2} \mathrm{~m} / \mathrm{s}$;

- transmission coefficient: $\mathrm{T}=5.0 \cdot 10^{-3}$ to $9.0 \cdot 10^{-2} \mathrm{~m}^{2} / \mathrm{s}$;

- groundwater level is very near to the terrain surface $(<6 \mathrm{~m})$;

- the min value of water level is during November and December, and max - in May and June.

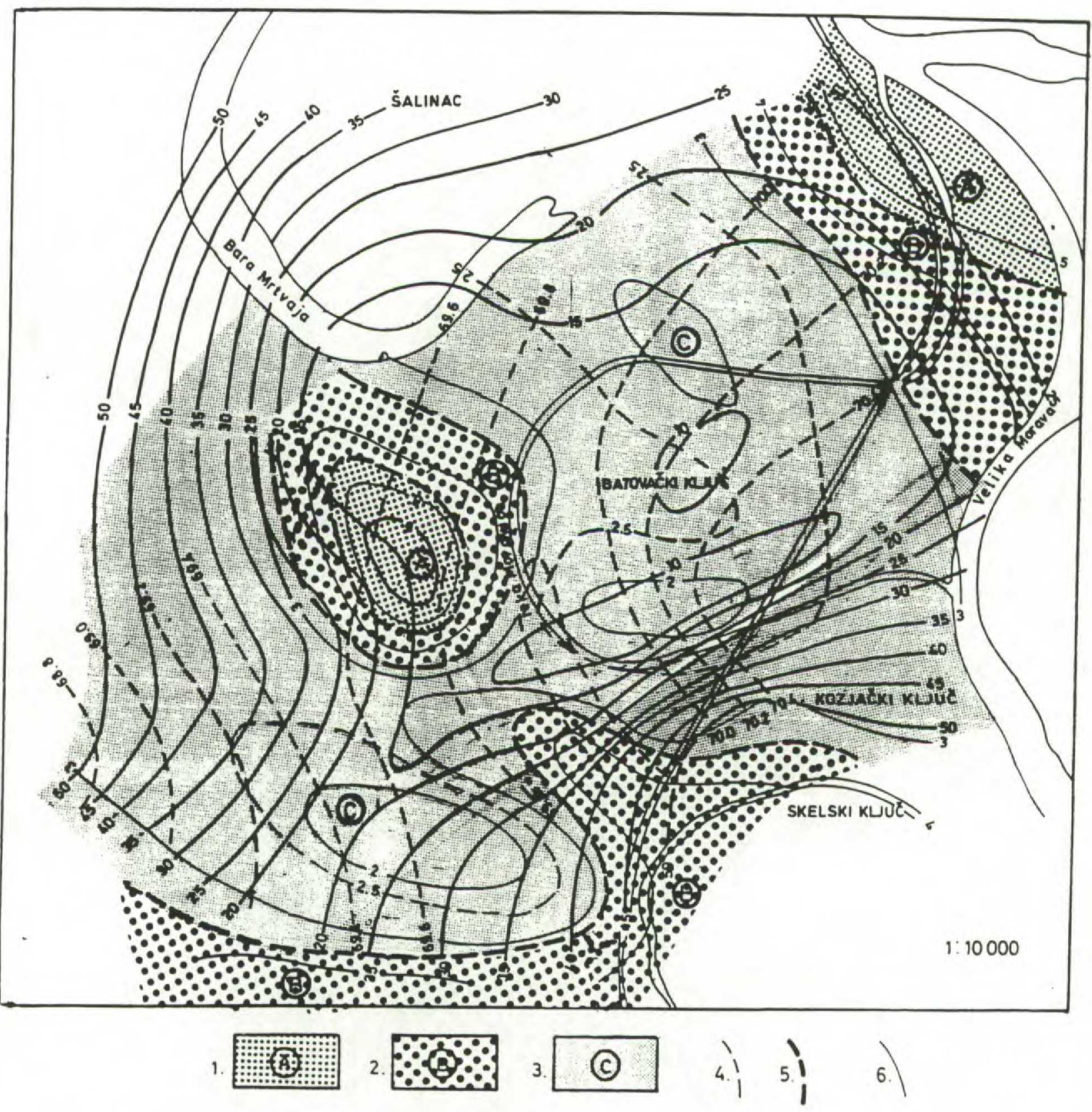

Fig.2. Mapping the aquifer vulnerability of the Salinac field area according to the results of hydrogeophysical exploration (1: 10000). 1. A category; 2. B category; 3. C category; 4. Thickness contours of the aquifer vulnerability; 5. Contours of the aquifer footwall; 6 . Contours of the aquifer thickness for the max groundwater level (Komatina S., 1996). 
In comparison with hydrogeological data, results of geophysical exploration for thickness of hanging-wall, groundwater level and lithological characteristics of rocks were satisfactory. However, filtration coefficient is under the question, because it was not paid enough attention to that value during the previous hydrogeological exploration.

Based on the results, zoning of the study area according to the aquifer vulnerability has been done. According to the mentioned criteria, the three main categories of water-bearing horizons according to its natural protection against pollution are distinguished:

1. A category - water-bearing horizon protected: aquifer covered by impermeable clayey layer, over than $5 \mathrm{~m}$ thick; thickness of aeration zone in $\max \mathrm{GWL}$ : $>4.0 \mathrm{~m} ; \mathrm{K}$ for hanging-wall sediments: $<5.0 \times 10^{-8} \mathrm{~m} / \mathrm{s}$.

2. B category - water-bearing horizon conditionally protected: aquifer covered by lowpermeable layer (silty sand, silty clay, $3.5-5.0 \mathrm{~m}$ thick; aeration zone in max GWL: $3.0-4.0 \mathrm{~m}$ thick; $\mathrm{K}=5.0 \times 10^{-8}$ to $1.0 \times 10^{-7} \mathrm{~m} / \mathrm{s}$.

3. C category - water-bearing horizon unprotected: aquifer covered by fine-grained clayey sands less than $3.5 \mathrm{~m}$ thick; aeration zone: $<3.0 \mathrm{~m} ; \mathrm{K}>1.0 \times 10^{-7} \mathrm{~m} / \mathrm{s}$.

Appropriate severe measures of groundwater source sanitary protection were determined for the area of the mouth of the V.Morava river into the Danube (Djerdap zone), where high content of pesticides, detergents and phenols were distinguished. The potential risk from pollution is expected especially near great towns of the area from industrial waste waters and agricultural chemicals.

According to the hydrogeophysical analysis, land-use planning and development of strategy for groundwater protection and management was possible.

\section{REFERENCES}

Komatina S., 1996. Geophysics in some hydrogeological problems solving. ICEC-96; UNESCO; p.143.

Komatina S., 1997. Application of geophysical methods in evaluation of groundwater vulnerability to pollution. Ph.D.thesis; TEMPUS Center; University of Novi Sad; Novi Sad; $153 \mathrm{p}$. 